\title{
Vulvar lesion in Crohn's disease: a new case report
}

\section{Abstract}

The dermatological manifestations are, with the osteo-articular, the most frequent of the extra intestinal attacks of Crohn disease (CD). While some of them evolve alongside the digestive disease, others evolve independently. Sometimes they can even precede the appearance of intestinal manifestations by several months, which then poses diagnostic problem. The recto-vaginal fistulas and ovarian involvement in $\mathrm{CD}$ have been widely reported in the literature. ${ }^{1,2}$ However, there are few series reporting the genital complications of $\mathrm{CD}$, let alone regarding vulvar lesions. We report a new case of vulvar lesions in Crohn disease.

Keywords: crohn disease, recto-vaginal fistulas, vulvar lesions, granuloma, Anatomopathological study, Pelvic MRI
Volume 10 Issue 6 - 2019

\author{
Lkousse MA, Gharbi K,A El farouki, Ismail Y, \\ Atmani J, Ait errami A, Oubaha S, Semlani K, \\ Krati Z \\ Department of Hepato-Gastro-Enterology, Mohammed VI \\ University Hospital, Morocco
}

Correspondence: Lkousse Mohammed Amine, Department of Hepato-Gastro-Enterology, Mohammed VI University Hospital, University Mohammed VI, Oujda, Morocco, Tel +2 I 26 I I I88323, Email medamine.Iko@gmail.com

Received: November II, 2019 | Published: December 12, 2019

\section{Case presentation}

A 30-year-old divorced woman with 2 children was followed for $\mathrm{CD}$ evolving for 7 years and treated with mesalazine. The patient did no longer consult for 5years. When she came back, the patient reported bloody diarrhea at the rate of 3 to 4 stools/day associated with tenesmus, evolving by flares/remission and pelvic pain.

Clinically, the perineum was retracted with multiple external fistulous orifices, some of which are budding. There was also a remodeled vulva, a painful edema of the labia majora with a hypertrophied clitoris (Figure 1).

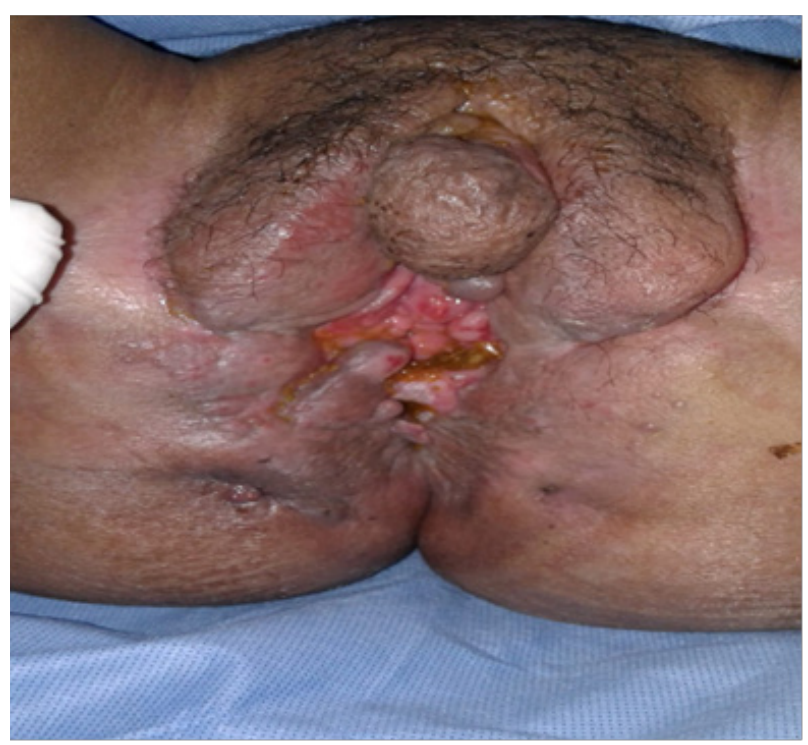

Figure I Remodeled vulva, edema of the labia majora with hypertrophied clitoris and multiple perineal fistulas.

Anatomopathological study of vulvar biopsies revealed a gigantoepithelioid granuloma without caseating necrosis, compatible with Crohn disease (Figure 2).

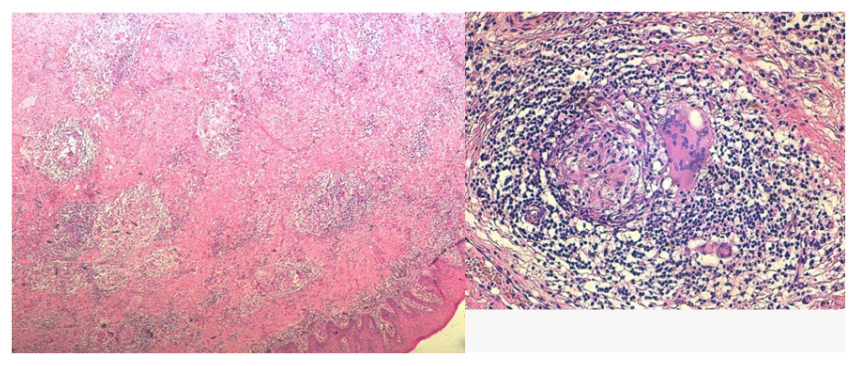

Figure $2 \mathrm{~A}$ giganto-epithelioid granuloma without caseous necrosis.

The colonoscopy showed a discontinuous inflammatory mucosa, with large ulcers up to left colic flexure. Above the mucosa was endoscopically normal. The anatomopathological examination of the colon biopsies gave the same results as those of the vulva in favor of Crohn disease. Pelvic MRI showed a large recto-vaginal fistula, multiple ano-perineal complex fistulas with perineal and pelvic infiltration, as well as circumferential and regular thickening of the extended rectum to the sigmoid colon (Figure 3).

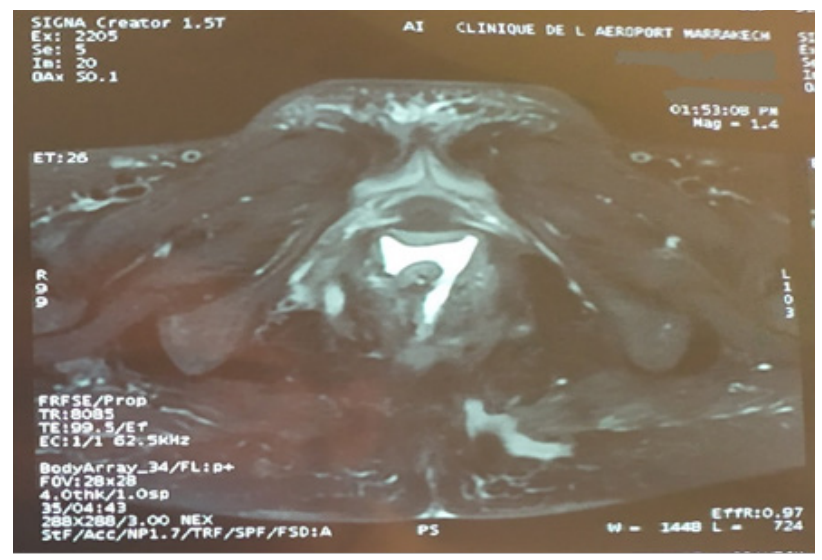

Figure 3 Pelvic MRI showing a large recto vaginal fistula (arrow). 
Therapeutically, the patient received infliximab at $5 \mathrm{mg} / \mathrm{kg}$ (including three injections at weeks 0,2 and 6 and then every 8 weeks) with onset of significant decrease in digestive, ano-perineal and vulvar manifestations. The surgical treatment had been proposed for the large recto-vaginal fistula.

\section{Discussion}

The crohn disease is a chronic granulomatous inflammatory disease that can affect any part of the digestive tract. It is associated with frequent and polymorphic extra-intestinal manifestations, the most frequent of which are musculoskeletal, dermatological, and ophthalmological and hepatobiliary. The dermatological manifestations during $\mathrm{CD}$ include reactive dermatosis, autoimmune dermatosis, diseases related to nutritional deficiencies, dermatological lesions secondary to treatment and specific granulomatous lesions. ${ }^{3}$ The latter form can affect the genitals, and other parts of the skin., ${ }^{4,5}$

The vulvar CD was described for the first time by Park et al. ${ }^{6}$ and there are few series in the literature reporting genital complications of $\mathrm{CD}$, let alone vulvar lesions. The involvement of the vulva during $\mathrm{CD}$ can occur either by direct extension from the perineal region or by metastasis. Metastatic Crohn disease is defined as granulomatous lesions separated from the affected regions of the digestive tract by a territory of healthy skin. ${ }^{7,8}$

In a review of the literature, Andreani et al found that $91 \%$ of cases of vulvar CD were metastatic, while only $9 \%$ were contiguous from the perineal region. ${ }^{10}$ In the same study, $25 \%$ of Vulvar CD cases had no digestive tract symptoms at the time of diagnosis.

Clinically, vulvar lesions can be associated to varying degrees with edema, papules, painful nodules, endovaginal fistulas, Bartholin's gland abscesses and ulcerations. ${ }^{1,2}$ The diagnosis must be evoked in the presence of deep vulvar linear ulcers called "knife-cut" or painful indurated labial edema, often asymmetrical.

The differential diagnoses of vulvar localization include sarcoidosis, tuberculosis, lymphogranuloma venereum, pyogenic infections, hidradenitis suppurativa, intertrigo and syphilitic lesions. The definitive diagnosis can only be made by performing a biopsy that reveals a non-caseating granulomatous lesion. ${ }^{9}$ The natural evolution of vulvar CD is unpredictable. Although some cases resolve spontaneously, the majority of cases persist. ${ }^{12,13}$ Due to its rarity, there are no randomized trials that suggest special treatment for vulvar Crohn disease. ${ }^{14}$ The oral steroids were associated with longterm improvement, ${ }^{15}$ but other medications like oral metronidazole, azathioprine and 6-mercaptopurine also showed good results. ${ }^{16}$

The Infliximab has been effective in cases of vulvar CD resistant to other immunosuppressants, including prednisolone, azathioprine and oral cyclosporine. ${ }^{8}$ The adalimumab and certolizumab have also been shown to be effective in dermatological Crohn disease. ${ }^{17,18}$ The surgery may be necessary for vulvar CD refractory to all medical treatments. Localized surgical excision frequently leads to localized recurrence and suboptimal wound healing. The radical vulvectomy is usually necessary in difficult cases. ${ }^{9}$

\section{Conclusion}

The vulvar localization is a rare extra-intestinal manifestation of Crohn disease. A multidisciplinary approach involving gastroenterologists, gynecologists, pathologists and dermatologists is recommended to identify this entity and to initiate appropriate treatment. As standardized therapy is lacking, the current therapeutic approach is case-by-case and can be escalated according to the severity of the disease.

\section{Acknowledgments}

None.

\section{Conflicts of interest}

Authors declare that there is no conflict of interest.

\section{References}

1. Andreani SM, Dang HH, Edwards DP, et al. Ovarian Crohn's disease: contiguous or metastatic? Inflamm Bowel Dis. 2006;12(11):1091-1092.

2. Andreani SM, Dang HH, Grondona P, et al. Rectovaginal fistula in Crohn's disease. Dis Colon Rectum. 2007;50(12):2215-2222.

3. Huang BL, Chandra S, Shih DQ. Skin manifestations of inflammatory bowel disease. Front Physiol. 2012;3:13.

4. Guest GD, Fink RL. Metastatic Crohn's disease: case report of an unusual variant and review of the literature. Dis Colon Rectum. 2000;43(12):1764-1766.

5. Palamaras I, El-Jabbour J, Pietropaolo N, et al. Metastatic Crohn's disease: a review. J Eur Acad Dermatol Venereol. 2008;22():1033-1043.

6. Parks AG, Morson BC, Pegum JS. Crohn's disease with cutaneous involvement. Proc R Soc Med. 1965;58:241-242.

7. Berkowitz EZ, Lebwohl M. Cutaneous manifestations of inflammatory bowel disease. J Eur Acad Dermatol Venereol. 2000;14(5):349-350.

8. Kafity AA, Pellegrini AE, Fromkes JJ. Metastatic Crohn's disease, A rare cutaneous manifestation. J Clin Gastroenterol. 1993;17(4):300-303.

9. Andreani SM, Ratnasingham K, Dang HH, et al. Crohn's disease of the vulva. Int J Surg. 2010;8(7):2-5.

10. Zhang Aj, Zhan SH, Chang H, et al. Crohn disease of the vulva without gastrointestinal manifestations in a 16-year-old girl. J Cutan Med Surg. 2015;19:81-83.

11. Barret M, de Parades, Battistella M, et al. Crohn's disease of the vulva. J Crohns Colitis. 2014;8(7):563-570

12. Makhija S, Trotter M, Wagner E, et al. Refractory Crohn's disease of the vulva treated with infliximab: a case report. Can J Gastroenterol. 2007;21(12):835-837.

13. Aberumand B, Howard J, Howard J. Metastatic Crohn's Disease: An Approach to an Uncommon but Important Cutaneous Disorder. BioMed Res Int. 2017;2017:8192150.

14. Bender-Heine A, Grantham JT, Zaslau S, Jansen R. Metastatic Crohn disease: a review of dermatologic manifestations and treatment. Cutis. 2017;99(6):E33-E40.

15. Hey F, Buchan PC, Littlewood JM, et al. Diferential diagnosis in child sexual abuse. Lancet. 1987;1:283

16. Keiler S, Tyson P, Tamburro J. Metastatic cutaneous Crohn's disease in children: case report and review of the literature. Pediatr Dermatol. 26(5):604-609.

17. Kiuru M, Camp B, Adhami K, et al. Treatment of metastatic cutaneous Crohn disease with certolizumab. Dermatol Online J. 2015;21(11):13030/qt17z6j2hv.

18. Miller FA, Jones CR, Clarke LE, et al. Successful use of adalimumab in treating cutaneous metastatic Crohn's disease: report of a case. Inflamm Bowel Dis. 2009;15(11):1611-1612. 